A.A. Krylov', Yu.V. Emelyanova ${ }^{1}$, E.S. Buyanova ${ }^{1}$, M.V. Morozova ${ }^{1}$, A.I. Vylkov', A.Yu. Chuykin ${ }^{2}$

${ }^{1}$ Ural Federal University 19 Mira St., 620000, Ekaterinburg, Russia ${ }^{2}$ Institute of High Temperature Electrochemistry UB RAS 20 Akademicheskaya St, 620137, Ekaterinburg, Russia

\title{
Materials based on BIFEVOX and bismuth or iron simple oxides nanopowders
}

Compositions of composite materials based on BIFEVOX and nanopowders of bismuth and iron oxides have been obtained. The absence of chemical interaction between the components has been proved, the total electrical conductivity of materials in the average temperature region has been determined. It has been shown that under the selected formation conditions, it has not yet been possible to achieve significant improvement of the functional characteristics of heterogeneous compositions in comparison with individual phases. However positive results on chemical and structural stability give way to further investigations.

Keywords: BIMEVOX; 0xygen-ion conductors; Electrical conductivity; Impedance spectroscopy.

Received: 22.09.2017; accepted: 17.10.2017; published: 20.10.2017.

(c) Krylov A.A., Emelyanova Yu.V., Buyanova E.S., Morozova M.V., Vylkov A.I., Chuykin A.Yu., 2017

\section{Introduction}

The family of solid electrolytes with the general formula $\mathrm{Bi}_{4} \mathrm{~V}_{2-x} \mathrm{Fe}_{x} \mathrm{O}_{11-\delta}$ (BIFEVOX) is characterized by high oxygen-ion conductivity at intermediate temperatures 550-950 K [1-5]. The high-temperature $\gamma$-modification of the BIFEVOX solid solutions with tetragonal structure (space group $14 / \mathrm{mmm}$ ) is obtained at $0.3 \leq x \leq 0.5$ iron concentration range. For this modification, the electrical conductivity versus temperature dependence is linear, and the activation energy at high temperatures has a value of $0.2-0.4 \mathrm{eV}$, which is characteristic of BIFEVOX. The transition to an ordered $\gamma^{\prime}$ modification with decreasing temperature is accompa- nied by a small change of slope of the $\lg \sigma$ - $10^{3} / T$ dependence and, accordingly, an increase in the activation energy to $0.5-$ $0.7 \mathrm{eV}$. The tetragonal $\gamma$-modification of the $\mathrm{Bi}_{4} \mathrm{~V}_{2-x} \mathrm{Fe}_{x} \mathrm{O}_{11-\delta}$ is sufficiently stable in a wide range of thermodynamic parameters $\left(T=298-1073 \mathrm{~K}, \lg p \mathrm{O}_{2}(\mathrm{~atm})=\right.$ -0.68 to -18.0$)[4,5]$. The change of the structure into the orthorhombic one occurs in atmosphere with low oxygen content $\left(\lg \mathrm{pO}_{2}(\mathrm{~atm})<-14.0\right)$ at temperatures above 773 K. However, decomposition of the sample does not occur. Evaluation of the structural and thermal stability of BIFEVOX in air at long time exposures (at least two weeks at the same temperature) 
in the temperature range $723-1083 \mathrm{~K}$ revealed no changes in the structure or appearance of any additional phases [6].

In the last decade composite electrolytes are actively studied as alternative electrolyte materials. It has been shown that in this way it is possible to improve the quality of the material and remove some disadvantages of individual electrolytes [7]. There are examples of creating composite materials with BIMEVOX as their components [8-11]. For the modification of BIFEVOX based electrolyte materials, the approach using simple oxides nanopowders is used in this paper.

\section{Experimental}

Samples of $\mathrm{Bi}_{4} \mathrm{~V}_{2-x} \mathrm{Fe}_{x} \mathrm{O}_{11-\delta}(x=0.3$, $0.5)$ solid solutions were synthesized according to the standard ceramic technology [2]. The preparation of nanopowders of bismuth and iron oxides was carried out by laser evaporation of a target and condensation of vapors in a working gas stream at the Institute of Electrophysics of the Ural Branch of the Russian Academy of Sciences. In this method a fiber ytterbium laser LS-1 with diode pumping was used. The average radiation power was $1000 \mathrm{~W}$ with a smooth adjustment from 20 to $100 \%$, the wavelength $1070 \mathrm{~nm}$, and the radiation regime continuous or modulated. The evaporation targets were prepared by pressing from a coarse-grained oxide powder followed by annealing at a temperature providing a partial sintering of the powder to provide mechanical strength of the compact. Composites were prepared by mechanically mixing of the corresponding powders with a simple oxide content of 10 to 50 wt.\%. The powders were pressed into pellets with a diameter of $10 \mathrm{~mm}$ on a hydraulic press in the form of pellets and annealed at $1073 \mathrm{~K}$.

The phase composition of the final solid oxide products was checked by X-ray powder diffraction (DRON-3 diffractometer, CuKa radiation, pyrolytic carbon monochromator, reflected beam). The particle size of the powders was determined using a laser dispersion analyzer SALD-7101 Shimadzu. The morphology of the obtained powders and their chemical composition were studied using a JEOL JSM6390 LA scanning electron microscope equipped with a JED-2300 energy dispersive X-ray detector. Thermal dilatometric analysis was performed on a DIL 402 C Netzsch dilatometer equipped with a vacuum furnace. Electrical conductivity measurements of the ceramic samples were performed on Elins Z-3000 impedance spectrometer in the temperature range $1073-473 \mathrm{~K}$.

\section{Results and discussion}
1. Synthesis and characterization of the materials
$\mathrm{Bi}_{4} \mathrm{~V}_{2-x} \mathrm{Fe}_{x} \mathrm{O}_{11-\delta}(x=0.3,0.5)$ samples, obtained by the standard ceramic tech- nology, are single-phase and have the structure of high-temperature tetragonal $\gamma$-modification (space group $14 / \mathrm{mmm}$ ). The average particle size of $\mathrm{Bi}_{4} \mathrm{~V}_{2-x} \mathrm{Fe}_{x} \mathrm{O}_{11-\delta}$
is in the range of $0.5-10 \mu \mathrm{m}$. The bismuth oxide nanopowder is single-phase, and is $\beta-\mathrm{Bi}_{2} \mathrm{O}_{3}$ with tetragonal structure. Iron oxide nanopowder contains three crys- talline phases where iron is in different oxidation states, so its composition is de- noted as $\mathrm{FeO}_{x}$. This is composed of $\mathrm{Fe}_{3} \mathrm{O}_{4}$ (magnetite) with its content $69 \%, \mathrm{Fe}_{2} \mathrm{O}_{3}$ 
(hematite, $10 \%$ ) and $\varepsilon$ - $\mathrm{Fe}_{2} \mathrm{O}_{3}(21 \%)$. The average particle size of nanopowders is in the range of $50-100 \mathrm{~nm}$.

In accordance with the results of the $\mathrm{XRD}$, the calculation of the unit cell parameters was carried out for $\beta-\mathrm{Bi}_{2} \mathrm{O}_{3}$ in the tetragonal structure (space group $I 4 / \mathrm{mmm}$ ), for $\mathrm{Fe}_{3} \mathrm{O}_{4}$ in cubic $(\mathrm{Fd}-3 \mathrm{~m})$, $\mathrm{Fe}_{2} \mathrm{O}_{3}$ for rhombohedral (space group $R-3 c$ ), $\varepsilon-\mathrm{Fe}_{2} \mathrm{O}_{3}$ for orthorhombic (space group Pna21) structure. The results are shown in Table 1. such transition upon heating in the reducing atmosphere while a $\gamma \leftrightarrow \beta$ phase transition is observed at $c a .850 \mathrm{~K}$. It is worth noting that final cooling curve recorded in air after reduction-oxidation cycling did not show indication of any transition. The unit cell parameters $a=3.919$ and $c=$ $15.509 \AA$ of the cooled sample were found by XRD to remain practically unchanged as compared to those of $\mathrm{Bi}_{4} \mathrm{~V}_{1.5} \mathrm{Fe}_{0.5} \mathrm{O}_{11-\delta}$ before the reduction-oxidation treatment. Aforementioned results indicate obviousTable 1

Crystal structure parameters of the materials

\begin{tabular}{c|c|c|c} 
Composition & $a \pm 0.001, \AA$ & $b \pm 0.001, \AA$ & $c \pm 0.004, \AA$ \\
\hline $\mathrm{Bi}_{4} \mathrm{~V}_{1.7} \mathrm{Fe}_{0.3} \mathrm{O}_{11-\delta}$ & 3.919 & 3.919 & 15.468 \\
\hline $\mathrm{Bi}_{4} \mathrm{~V}_{1.5} \mathrm{Fe}_{0.5} \mathrm{O}_{11-\delta}$ & 3.918 & 3.918 & 15.524 \\
\hline$\beta-\mathrm{Bi}_{2} \mathrm{O}_{3}$ & 7.729 & 7.729 & 5.648 \\
\hline $\mathrm{Fe}_{3} \mathrm{O}_{4}$ & 8.356 & 8.356 & 8.356 \\
\hline $\mathrm{Fe}_{2} \mathrm{O}_{3}$ & 5.034 & 5.034 & 13.727 \\
\hline$\varepsilon-\mathrm{Fe}_{2} \mathrm{O}_{3}$ & 5.091 & 8.804 & 9.446
\end{tabular}

Taking into account that the BIMEVOX materials are non-stable in a reducing atmosphere as well as $\mathrm{Bi}_{4} \mathrm{~V}_{2-x} \mathrm{Fe}_{x} \mathrm{O}_{11-\delta}$ undergoes transition from tetragonal structure to orthorhombic one in air at ca. $773 \mathrm{~K}$ without decomposition $[4,5]$ the sample of $\mathrm{Bi}_{4} \mathrm{~V}_{1.5} \mathrm{Fe}_{0.5} \mathrm{O}_{11-\delta}$ prepared accordingly was investigated in the reducing atmosphere with $\log \left(\mathrm{pO}_{2} / \mathrm{atm}\right)$ $<-14.0$ by means of dilatometry equipped with special chamber in order to reveal a possible structure transition. The study was carried out with sequential change of gas atmosphere from air via argon to mixture of argon and hydrogen, and back to air in the heating and cooling cycles. When the sample was found to be heated in air a slight change in the slope of curve 1 at $890 \mathrm{~K}$ (see Fig. 1) corresponding to an order-disorder type $\gamma \leftrightarrow \gamma^{\prime}$ phase transition [12] is observed. However, there is no

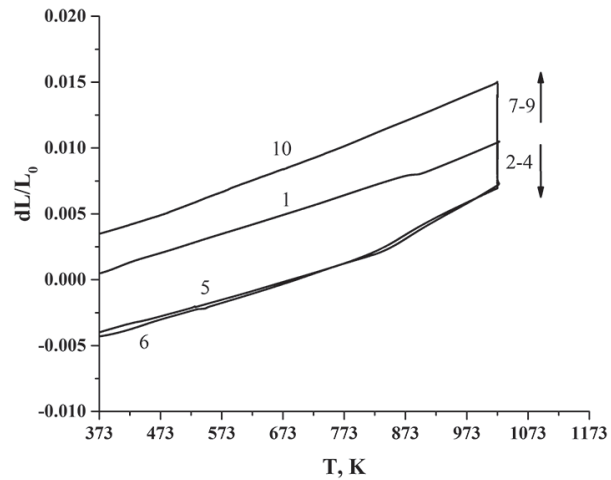

Fig. 1. Thermal strain of the $\mathrm{Bi}_{4} \mathrm{~V}_{1.5} \mathrm{Fe}_{0.5} \mathrm{O}_{11-\delta}$ sample: 1 - heating up to $1023 \mathrm{~K}$ in air; 2 - 30 minutes holding in air at $1023 \mathrm{~K}$; $3-1$ hour holding in argon at $1023 \mathrm{~K}$; 4- 2 hours holding in argon-hydrogen mixture at $1023 \mathrm{~K}\left(50 \% \mathrm{H}_{2}\right.$ and $50 \% \mathrm{Ar}$ for this and next three steps); 5 - cooling in argon-hydrogen mixture, 6 - second heating in air-argon mixture; 7 - 30 minutes holding in argon-hydrogen mixture at $1023 \mathrm{~K}$; 8 - 1 hour holding in argon at $1023 \mathrm{~K}$; $9-3.5$ hours holding in air at $1023 \mathrm{~K}$, 10 - cooling in air 
ly in favor of high resistance of the BIFEVOX structure to alteration under reducing conditions. The value of the linear thermal expansion coefficient (LTEC) of the BIFEVOX before and after the oxidation-reduction cycle also did not change significantly and remained in the range $17-19 \cdot 10^{-6} \mathrm{~K}^{-1}$ (Fig. 2). Annealing in hydrogen atmosphere of the $\mathrm{Bi}_{4} \mathrm{~V}_{1.7} \mathrm{Fe}_{0.3} \mathrm{O}_{11-\delta}$ sample at $1073 \mathrm{~K}$ for 8 hours was carried out to estimate the possibility of decomposition of the $\mathrm{Bi}_{4} \mathrm{~V}_{2-x} \mathrm{Fe}_{x} \mathrm{O}_{11-\delta}$ series at $\lg \mathrm{PO}_{2}(\mathrm{~atm})<-14.0$. In addition to the $\mathrm{Bi}_{4} \mathrm{~V}_{2-x} \mathrm{Fe}_{x} \mathrm{O}_{11-\delta}$ lines, peaks corresponding to $\mathrm{BiVO}_{4}$ and $\mathrm{Bi}_{2} \mathrm{O}_{3}$ (or solid solutions

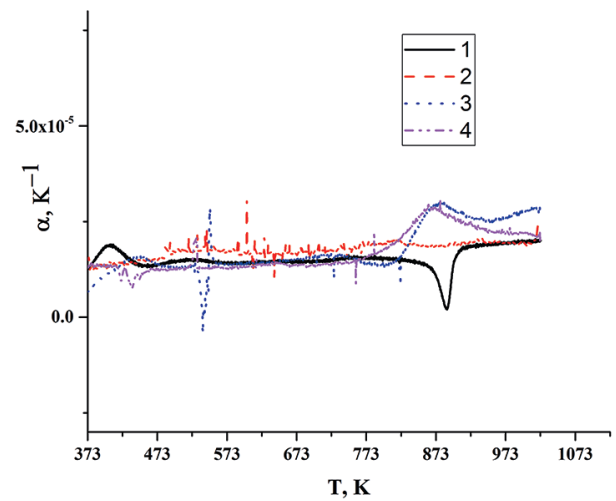

Fig. 2. LTEC change versus temperature:

1 - first heating in air, 2 - cooling in air after reduction-oxidation cycle, 3 - heating in argon-hydrogen mixture, 4 - cooling in argon-hydrogen mixture

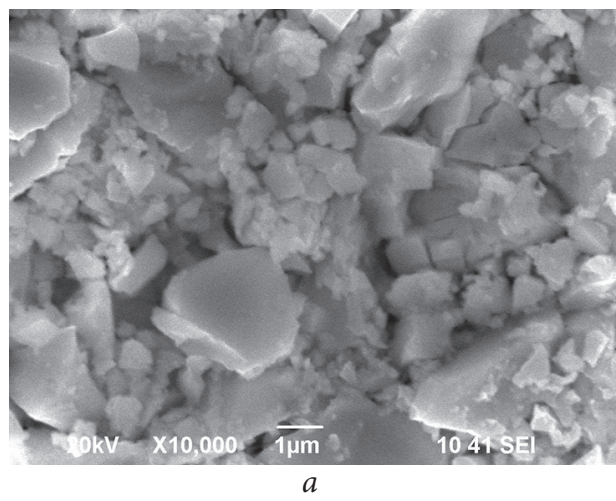

based on them) as well as to metallic iron were found on the X-ray diffraction pattern of the sample. These results show that samples of the BIFEVOX system, being annealed in air after the reduction, return to their original state with the same crystal structure.

2. Preparation and characterization of composite materials.

$\mathrm{X}$-ray phase analysis was used to test the possible interactions in the composite by annealing pellets of $\mathrm{Bi}_{4} \mathrm{~V}_{1.7(1.5)}$ $\mathrm{Fe}_{0.3(0.5)} \mathrm{O}_{11-\delta} / x$ wt. $\% . \mathrm{Bi}_{2} \mathrm{O}_{3}\left(\mathrm{FeO}_{x}\right)$ composites at $1073 \mathrm{~K}$. All X-ray diffraction patterns contain only composite components lines, without extra reflexes.

As an additional method for determining the phase and element composition of composites, the scanning electron microscopy (SEM) method with the energy-dispersive microanalysis was used. For the sintered samples, the surface and cross-section of the composite pellets were examined. It was established that the surface of the samples is porous, consists of grains of various shapes and sizes, the visual contrast is determined by the topography of the sample surface (Fig. 3).

Large grains of BIFEVOX and fine grains of nanopowder particles are clearly

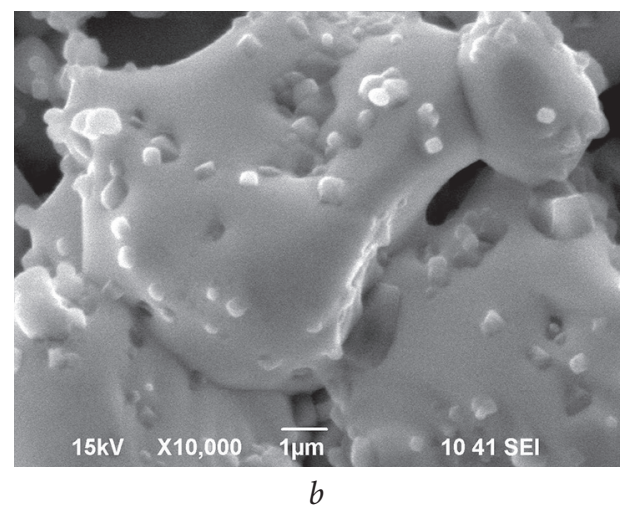

Fig. 3. The images of the surface of the composite samples: $a-\mathrm{Bi}_{4} \mathrm{~V}_{1.5} \mathrm{Fe}_{0.5} \mathrm{O}_{11-\delta} / 40$ wt. $\% . \mathrm{Bi}_{2} \mathrm{O}_{3} ; b-\mathrm{Bi}_{4} \mathrm{~V}_{1.7} \mathrm{Fe}_{0.3} \mathrm{O}_{11-\delta} / 10$ wt.\%. $\mathrm{FeO}_{x}$ 
visible, the iron oxide particles being aggregated to a lesser extent and covering the coarse grains of the BIMEVOX complex oxide. The particles of bismuth oxide are combined into aggregates and fill the space between the coarse BIMEVOX particles. The chemical composition of the particles was estimated by energydispersive X-ray spectroscopy (EDX), and results correspond to the nominal ratio of elements in simple and complex oxides, which additionally indicates the absence of interaction in the composites under the selected processing conditions. An example of the X-ray dispersion energy spectrum of a surface of the $\mathrm{Bi}_{4} \mathrm{~V}_{1.7} \mathrm{Fe}_{0.3} \mathrm{O}_{11-\delta} / 10$ wt.\%. $\mathrm{FeO}_{x}$ composite is shown in Fig. 4.

Determination of the electrochemical characteristics of the composite materials was carried out by the impedance spectroscopy method. Complex plane plots of the BIFEVOX solid solutions consist of two joint half-circles, showing behavior typical for the BIMEVOX family ionic conductors [2].

Fitting of the Cole-Cole plots was performed using the equivalent electrical circuits method [2]. Typical temperature dependences of the total conductivity are

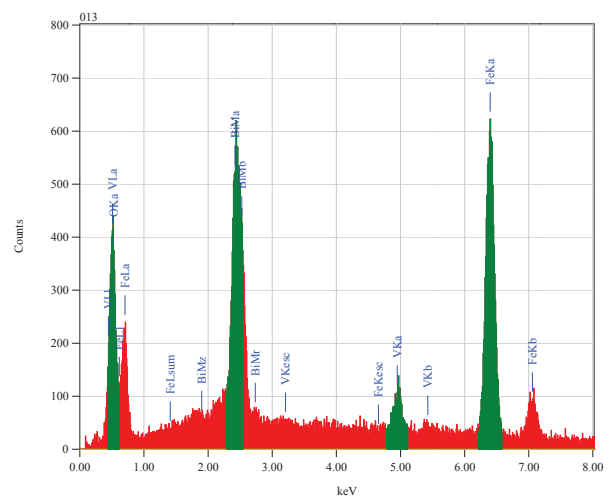

Fig. 4. EDX spectrum of the $\mathrm{Bi}_{4} \mathrm{~V}_{1.7} \mathrm{Fe}_{0.3} \mathrm{O}_{11-\delta} / 10$ wt. \%. $\mathrm{FeO}_{x}$ composite surface shown in Fig. 5. The dependences of the total conductivity on temperature for the composites studied have the form characteristic for the $\gamma$-modification of BIFEVOX. The change of slope is observed in the dependencies at the temperature range $750-850 \mathrm{~K}$. It corresponds to the transition of BIFEVOX to an ordered $\gamma^{\prime}$ modification with decreasing temperature and is accompanied by the increase of the activation energy from 0.4 to $0.7-0.8 \mathrm{eV}$. The behavior of all $\lg \sigma-10^{3} / T$ dependencies, corresponding to the composites with different content and nature of the simple oxide added is similar.

As the concentration of the simple oxide increases, the conductivity decreases. This situation is typical for the entire temperature range. This is probably due to an increase in the concentration of the less conducting phase, which are the simple oxides used in comparison with pure BIFEVOX. For example, according to $[13,14]$, for the $\beta-\mathrm{Bi}_{2} \mathrm{O}_{3}$ at $873 \mathrm{~K}$ the value of the total electrical conductivity is

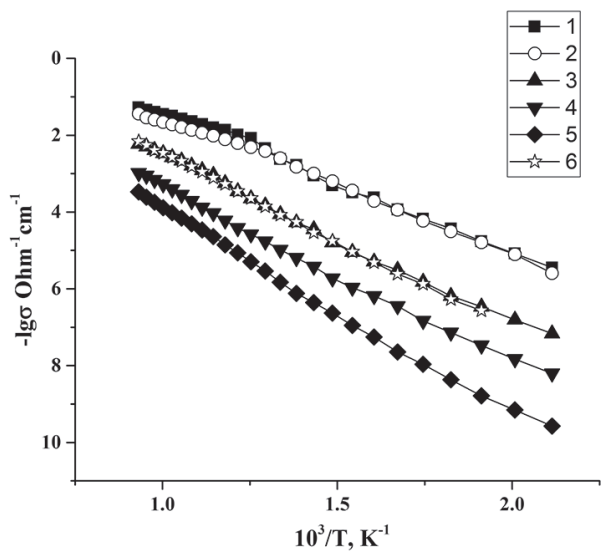

Fig. 5. Total electrical conductivity versus temperature: $1-\mathrm{Bi}_{4} \mathrm{~V}_{1.7} \mathrm{Fe}_{0.3} \mathrm{O}_{11-\delta}$; $2-\mathrm{Bi}_{4} \mathrm{~V}_{1.5} \mathrm{Fe}_{0.5} \mathrm{O}_{11-\delta} ; 3-\mathrm{Bi}_{4} \mathrm{~V}_{1.5} \mathrm{Fe}_{0.5} \mathrm{O}_{11-\delta} / \mathrm{wt} . \%$ $\mathrm{FeO}_{x} ; 4-\mathrm{Bi}_{4} \mathrm{~V}_{1.5} \mathrm{Fe}_{0.5} \mathrm{O}_{11-\delta} / \mathrm{wt} . \% \mathrm{FeO}_{x}$; $5-\mathrm{Bi}_{4} \mathrm{~V}_{1.5} \mathrm{Fe}_{0.5} \mathrm{O}_{11-\delta} / 40$ wt. $\% \mathrm{Bi}_{2} \mathrm{O}_{3}$; $6-\mathrm{Bi}_{4} \mathrm{~V}_{1.7} \mathrm{Fe}_{0.3} \mathrm{O}_{11-\delta} / 10$ wt. $\% \mathrm{Bi}_{2} \mathrm{O}_{3}$ 
$\sim 10^{-3} \mathrm{Ohm}^{-1} \mathrm{~cm}^{-1}$, for $\mathrm{Bi}_{4} \mathrm{~V}_{1.7} \mathrm{Fe}_{0.3} \mathrm{O}_{11-\delta}$ in our work it is $1.5 \times 10^{-2} \mathrm{Ohm}^{-1} \mathrm{~cm}^{-1}$. The effect of an increase of the overall electrical conductivity values of composite samples, which could be associated with a possible increase in the sintering quality of the bars, is not observed.

\section{Conclusions}

Thus, compositions of composite materials based on BIFEVOX and nanopowders of bismuth and iron oxides have been obtained, the absence of interaction between them has been proved, the total electrical conductivity of materials in the region of average temperatures has been determined. It has been shown that, un- der the selected formation conditions, it has not yet been possible to achieve significant improvement of the functional characteristics of heterogeneous compositions in comparison with individual phases. However, the results obtained can serve as a basis for further searching for optimal solutions.

\section{Acknowledgements}

The work was partially supported by the Scholarship of the President (SP-3376.2016.1) and Russian Foundation for Basic Research (project No 17-53-04098).

\section{References}

1. Garcia-Gonzalez E, Arribas M, Gonzalez-Calbet JM. Short-Range-Long-Range Order Transformation in the $\mathrm{Bi}_{4} \mathrm{~V}_{2-x} \mathrm{Fe}_{x} \mathrm{O}_{11-y}$ Series. Chem Mater. 2001;13(1):96-102. DOI:10.1021/cm0003929.

2. Buyanova ES, Petrova SA, Emel'yanova YuV, Blinova AL, Morozova MV, Zhukovskii VM, Zhuravlev VD. Preparation, Structure, and Charge Transport Characteristics of BIFEVOX Ultrafine Powders. Russ J Inorg Chem. 2009;54(8):1193-204. DOI: 10.1134/S0036023609080051.

3. Pena V, Rivera A, Leon C, Santamaria J, Garcia-Gonzalez E, Gonzalez-Calbet JM. Correlated Oxygen Diffusion in BIFEVOX. Chem Mater. 2002;14(4):1606-9. DOI:10.1021/cm010743z.

4. Zhukovskii VM, Buyanova ES, Emel'yanova YuV, Morozova MV, Shafigina RR, Zakharov RG, Zhuravlev VD. Synthesis, Structure, and Conductivity of BIMEVOX Oxide Ceramics. Russ J Electrochem. 2009;45(5):512-9. DOI:10.1134/ S1023193509050024.

5. Morozova MV, Buyanova ES, Emelyanova JuV, Zhukovskiy VM, Petrova SA. Highconducting oxide ceramics BIMEVOX: synthesis, structure, properties. Solid State Ionics. 2011;192(1):153-7. DOI:10.1016/j.ssi.2010.04.020.

6. Morozova MV, Buyanova ES, Petrova SA, Khisametdinova VV, Emel'yanova YuV, Shatokhina AN, Zhukovskii VM. Structural and Thermal Stability of BIMEVOX Oxygen Semiconductors. Russ J Electrochem. 2011;47(4):448-52. DOI:10.1134/ S1023193511040100.

7. Rondao AIB, Patrıcio SG, Figueiredo FML, Marques FMB. Composite electrolytes for fuel cells: Long-term stability under variable atmosphere. Int J Hydrogen Energy. 2014;39:5460-9. DOI:10.1016/j.ijhydene.2013.12.125. 
8. Fuierera P, Maiera M, Exner J, Moos R. Anisotropy and thermal stability of hot-forged BICUTIVOX oxygen ion conducting ceramics. J Eur Ceram Soc. 2014;34(4):943-51 DOI:10.1016/j.jeurceramsoc.2013.10.016.

9. Sunarso J, Baumann S, Serra JM, Meulenberg WA, Liu S, Lin YS, Diniz da Costa JC. Mixed ionic-electronic conducting (MIEC) ceramic-based membranes for oxygen separation. J Membrane Science. 2008;320(1-2):13-41. DOI: org/10.1016/j.memsci.2008.03.074.

10. Sabolsky EM, Razmyar S, Sabolsky K. Nano-ceria enhancement of $\mathrm{Bi}_{2} \mathrm{Cu}_{0.1} \mathrm{~V}_{0.9} \mathrm{O}_{5.35}$ (BICUVOX) ceramic electrolytes. Mater Lett. 2012;76:47-50. DOI:10.1016/j.matlet.2012.02.048.

11. Piva RH, Piva DH, Venturini J, Floriano R, Morelli MR. Inhibition of order-disorder phase transition and improvements in the BICUVOX.1 properties by using yttria-stabilized zirconia particles. Ceram Int. 2014;41(1):171-7. DOI:10.1016/ j.ceramint.2014.08.055.

12. Buyanova ES, Shafigina RR, Morozova MV, Emel'yanova YuV, Khisametdinova VV, Zhukovskii VM, Petrova SA, Tarakina NV. Electrochemical Characteristics, Thermal and Chemical Compatibility in the $\mathrm{La}_{0.7} \mathrm{Sr}_{0.3} \mathrm{CoO}_{3}$ Electrode- $\gamma$-BIFEVOX Electrolyte System. Russ J Inorg Chem. 2013;58(5):554-8. DOI:10.1134/S0036023613050033.

13. Sammes NM, Tompsett GA, Näfe H, Aldinger F. Bismuth based oxide electrolytes- structure and ionic conductivity. J Eur Ceram Soc. 1999;19(10):1801-26. DOI:10.1016/S0955-2219(99)00009-6.

14. Kharton VV, Marques FMB, Atkinson A. Transport properties of solid oxide electrolyte ceramics: a brief review. Solid State Ionics. 2004;174:135-49. DOI:10.1016/j. ssi.2004.06.015.

\section{Cite this article as:}

Krylov AA, Emelyanova YuV, Buyanova ES, Morozova MV, Vylkov AI, Chuykin AYu. Materials based on BIFEVOX and bismuth or iron simple oxides nanopowders. Chimica Techno Acta. 2017;4(3):202-8. DOI:10.15826/chimtech/2017.4.3.05. 